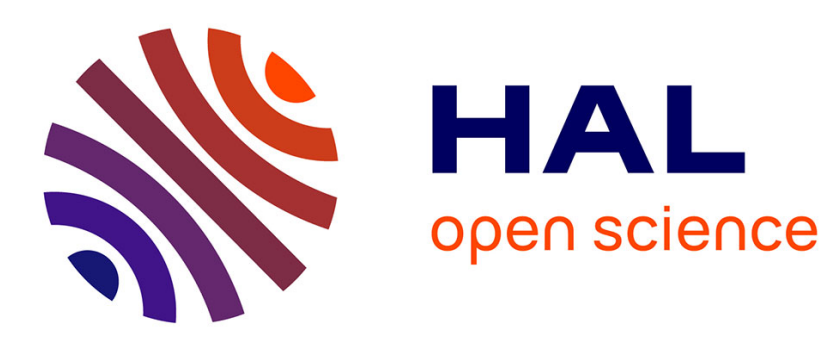

\title{
FORMATION AND PROPERTIES OF MBE GROWN AlSb-GaSb (100) INTERFACES
}

\author{
C. Raisin, H. Tegmousse, L. Lassabatère
}

\section{To cite this version:}

C. Raisin, H. Tegmousse, L. Lassabatère. FORMATION AND PROPERTIES OF MBE GROWN AlSb-GaSb (100) INTERFACES. Journal de Physique Colloques, 1987, 48 (C5), pp.C5-77-C5-80. 10.1051/jphyscol:1987512 . jpa-00226703

\section{HAL Id: jpa-00226703 https://hal.science/jpa-00226703}

Submitted on 1 Jan 1987

HAL is a multi-disciplinary open access archive for the deposit and dissemination of scientific research documents, whether they are published or not. The documents may come from teaching and research institutions in France or abroad, or from public or private research centers.
L'archive ouverte pluridisciplinaire HAL, est destinée au dépôt et à la diffusion de documents scientifiques de niveau recherche, publiés ou non, émanant des établissements d'enseignement et de recherche français ou étrangers, des laboratoires publics ou privés. 
FORMATION AND PROPERTIES OF MBE GROWN ALSb-GaSb (100) INTERFACES

\author{
C. RAISIN, H. TEGMOUSSE and L. LASSABATERE \\ Université des Sciences et des Techniques du Languedoc, \\ Laboratoire d'Etudes des Surfaces. Interfaces et Composants, \\ CNRS-UA 04-0787, Place Eugène Bataillon, F-34060 Montpellier \\ Cedex, France
}

Ce travail porte sur l'élaboration par jets moléculaires des interfaces GaSb-AISb et AISb-GaSb, et sur l'étude pas à pas par diffraction d'électrons rapides, par effet Auger, par mesures du travail de sortie de la surface de départ et de l'interface en formation. On précise ainsi la qualité électronique des surfaces, interfaces, et, met en évidence des diffusions d'Al pour l'interface GaSb/AISb et pas de diffusion notable de Ga pour A1Sb/GaSb.

In this paper, we present results, we have obtained on GaSb-AISb or AlSb-GaSb interfaces grown by MBE. We first focuss on the surface properties obtained by AES, RHEED, work function topographies. Then, we describe the formation of the interface and the evolution of its properties during growth. We detail AES and work function measurements and show At migration at the GaSb/AlSb interface and no noticeable $G$ a diffusion at the $A I S b / G$ aSb interface.

\title{
I - INTRODUCTION.
}

For a few years, research on GaSb and alloys have been increasing continuously. Type I ( GaSb-GaAISb) or type II (GaSb - InAS) superlattices present interesting properties resulting particularly from strain at the interface and from relevant effects. However, this strain is not too high and these interfaces are good enough to be used in electronic devices and in quantum well structure. Photodetector and lasers integrating these interfaces and optical fibers achieved with these materials are promising. New developments can be expected in the next future.

$M B E$ is now intensively used, to grown these materials (1-5).

In this paper, we present results relevant to the elaboration's conditions, to the physico-chemistry and to the electronic properties of GaSb-AlSb interfaces we have grown by this technique.

\section{II - GROWTH APPARATUS AND CONDITIONS}

The samples were grown in a MBE system which has been previously described (6). This system which was home made, is composed of three chambers.

-One evaporation chamber with 7 Riber 110 PBN/cells, with a RHEED, apparatus and a mass spectrometer.

-One chamber for Auger and work function studies.

- One chamber to keep in stock several samples.

The vacuum in the three chamber is in the $10^{-11}$ Torr range. The samples can be transfered from one chamber to another without breaking the vacuum. Under these conditions, we are able to characterize all the phases of the interface formation. Furthermore, by using a Kelvin probe which is moved in front of the surface of the substrate or in front of the layer, we deduce information on the uniformity of the layer, on the work function $\$$ and on the photovoltage SPV. This last technique is very useful because it does not affect the properties of the interface during measurements. Its sensitivity is high and variations as small as $1.5 \mathrm{meV}$ can be detected. 


\section{III - SURFACE PREPARATION}

\section{1 - Substrate surface}

The samples 100 oriented, obtained from MCP wafer $(350 \mu)$ were first mechanically polished and etched in different chemical solutions. Studies of the surface composition having shown that the best results ( $\mathrm{small}$ concentration of $\mathrm{C}, 0$ ) were obtained with $\mathrm{Br}$-Methanol, we have used this solution.

The samples were then inserted into the chamber and heated at $300^{\circ} \mathrm{C}$. The surfaces prepared in this way show reproducible properties. The carbon concentration is low but they are covered by a thin oxyde layer. In order to eliminate it, substrates were annealed at $580^{\circ} \mathrm{C}$. Under these conditions, $\mathrm{Ga}_{2} \mathrm{O}_{3}, \mathrm{Sb}_{2} \mathrm{O}_{5}$, were craked and desorbed. But at this temperature, $\mathrm{Ga}$ and $\mathrm{Sb}$ do not evaporate congruently and the surface becomes Sb poor. In order, to avoid this depletion in Sb, we annealed the sample under a Sb flux $\left(10^{-9}\right.$ Torr $)$.

The surfaces prepared in this way were clean and ordered, and depending on the flux presented the following reconstruction : $(1 \times 3)$ for $\mathrm{Ga}$ rich surfaces, $(2 \times 3)$ for Sb rich surfaces.

Similar experiments with an As flux lead to the conclusion that the surface reconstruction is determined by the nature of the vapor flux. The reconstruction was characteristic of GaAs for an As flux, (on GaSb as well as on GaAs) and of GaSb for Sb flux on GaAs or GaSb.

Besides AES, we performed EELS and work function measurements. EELS showed the typical peaks corresponding to valence-band-conduction-band transitions, to $S b$ (4d), Ga (3d) core level excitation. Work function ( $\phi$ ) and surface photovoltage (SPV) topographies obtained by moving a metallic probe in front of the sample and measuring the contact potential difference and the surface photovoltage are presented in Fig. 1. For GaSb, SPV \# 0 and $\phi$ variation along the surface are smaller than $100 \mathrm{meV}$. The surface barrier if present, is small (it is not the case for GaAs substrate) and the variations in $\Phi$ probably result from variations of the electronic affinity.

2 - Layer surfaces.

Starting from the previous substrates, we have grown GaSb or Alsb layer (growth rate 1.5. $\mathrm{A} \% \mathrm{~s}$ for GaSb $0.5-5 \mathrm{~A}^{\circ} / \mathrm{S}$ for $\mathrm{AISB}-\mathrm{T}$ substrate \# + $580^{\circ} \mathrm{C}$, vacuum \# $10^{-9}$ Torr. These surface are clean and ordered but the work function and surface photovoltage topographies obtained immediatly after the growth, show noticeable variations : the surfaces are not uniform (Fig. 1). Their electronic properties, very sensitive to small modifications, vary from point to point..

\section{III - INTERFACE FORMATION}

We have grown the following interface : $A 1 S b / G a S b$ substrates, $A 1 S b / G a S b \quad M B E$ grown/GaSb substrate, $G$ aSb/A1Sb MBE grown/GaSb.

In the case of the $A 1 S b / G a S b$ substrate, the interface was disturbed by the substrate morphology.

Therefore, we have grown AlSb or GaSb layers on a MCP substrate covered by a $1 \mu \mathrm{m}$ MBE grown GaSb buffer. Some results we have got by AES, work function measurements are given in Fig. 2. When growing AlSb on $G a S b, G$ a peaks decrease and $A 1$ peaks increase but $50 \mathrm{~A}^{\circ}$ of AlSb are enough to attenuate $G$ a peaks. Furthermore, the ratio of $\mathrm{Ga}(55 \mathrm{eV})$ peaks before and during AlSb growth, fastly decrases. $G$ a atoms $m$ ay diffuse into AISb but this diffusion is not significant.

In the case of the growth of GaSb over AlSb Al peaks and Al (68 eV) / Al (1395 eV) ratios progressively decrease when increasing the top layer thickness but $A 1$ is still detected for $150 \mathrm{~A}^{\circ}$ of $\mathrm{GaSb}$. Simultaneously the ratio Al (68 eV/Sb (26 eV) goes through a maximum for 1-2 $A^{\circ}$ of $G a S b$ and this illustrate an $A l$ transfer between the last layer of AISb and the first layer of GaSb.

Therefore, $\mathrm{Al}$ atoms diffuse into $\mathrm{G}$ aSb and this diffusion is significative and result in noticeable modification. Indeed measurements of work function variations shown in Fig.2 emphasize high modifications in $\phi$ during the first monolayer growth. first increases subsequently reaches a maximum value for half a monolayer, then decreases and finally becomes equal to GaSb work function 


\section{DISCUSSIONS}

Diffusion of $A$ in into $G$ aSb cannot be explained by taking into account the heat of formation of GaSb and AISb ; the heat of formation of AISD is higher than that of GaSb and the situation is not favorable to an $A$ l exchange from AlSb to GaSb.

However, the values of the heat of formation found in the literature do not exactly correspond to the conditions of these experiments and to interface reaction. Therefore from a thermodynamical point of view, $m$ ay be this exchange cannot be excluded. Furthermore, we can also envisage the formation of $G$ a clusters in top of ATSb. The energy needed to promote the exchange could be supplied by the formation of these clusters as it is the case for metal deposits on III-V compounds (7). However, in view of thermodynamical data, the hypothesis of the formation of small clusters of $A l$ (on top of AlSb) supplying $A l$ atoms for the diffusion into GaSb seems more probable.

The work function variations can be associated with this exchange. The last layer of AlSb lose Al atoms and the first layer of GaSb seems Sb poor. As Al and Sb vacancies induce, respectively donor and acceptor states (8), variations can be explained by an electron transfer from the last layer of AlSb to the first layer of $\mathrm{GaSb}$ and by a resulting increase in electronic affinity $X$. When the thickness of the layer increases, $\phi$ varies in order to get the value characteristic of the thick layer. The $50-70 \mathrm{~A}^{\circ}$ correspond to the depth of the interface.

\section{IV - CONCLUSION}

Surfaces prepared obtain by MBE present electronic properties (affinity, barrier) much more uniform than other surfaces (cleaved or chemically cleaned). The growth of $A l S b / G a S b$ and $G a S b / A l S b$ brings to the fore the diffusion of $A l$ which cannot be simply explained by considering the heats of formation. Possibly this diffusion is assisted by strains in the layer (9).

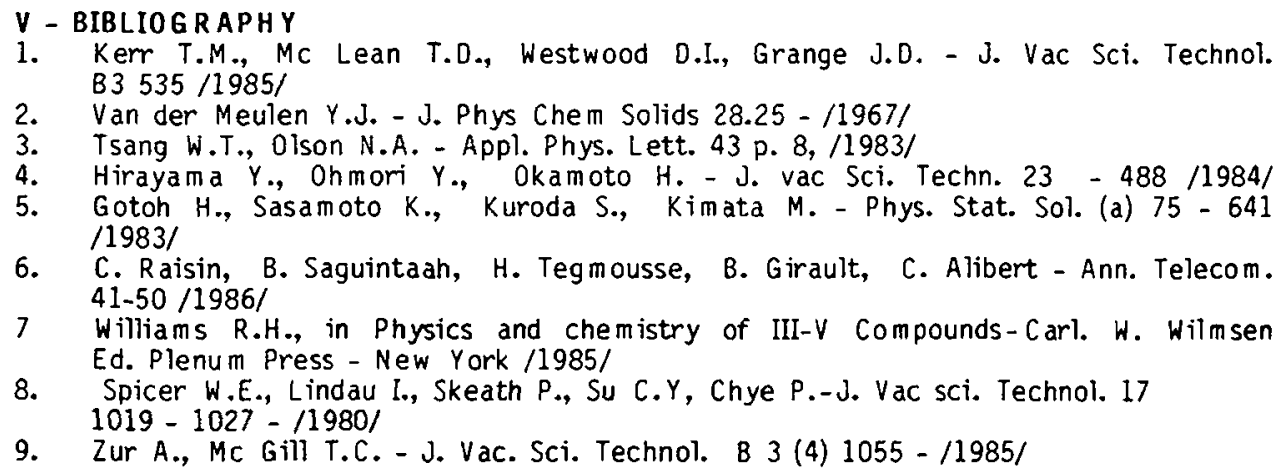



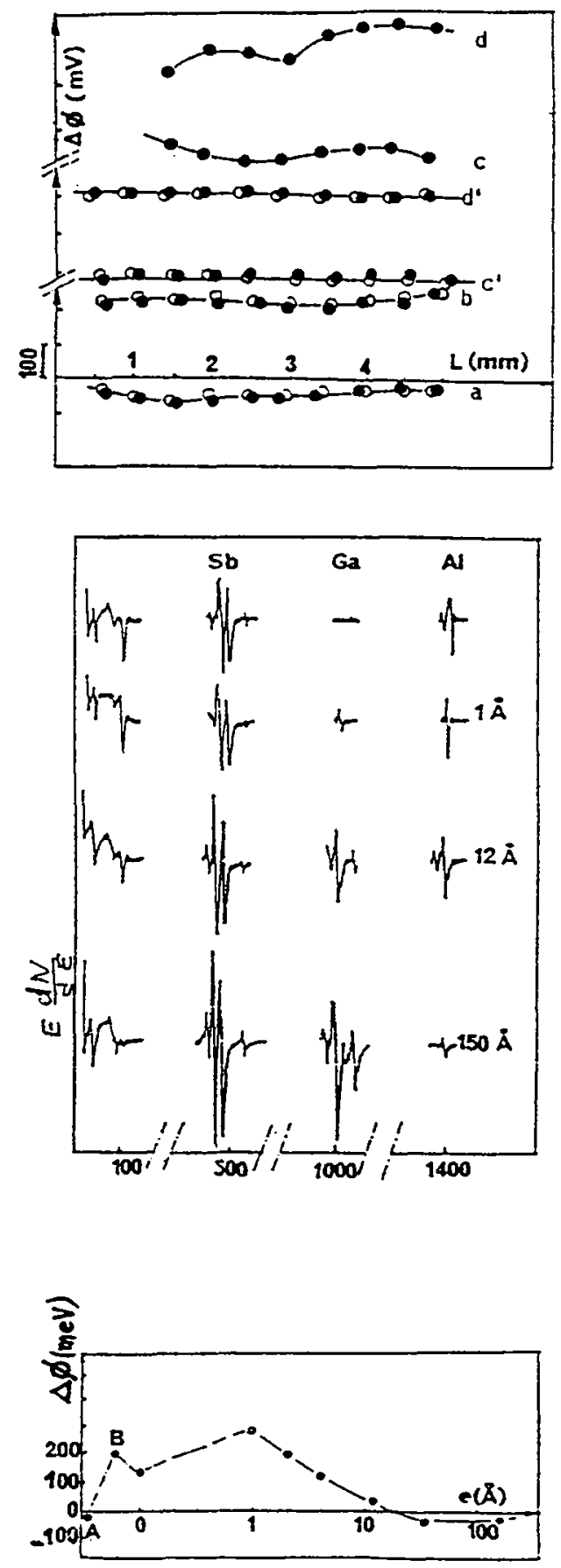

Work function and surface photovoltage topographies

1.a $n$ type GaSb etched surface

I.b $n$ type $G$ aSb annealed at $580^{\circ}$ under $\mathrm{Sb}$ flux : surface clean and ordered

1.c MBE grown p type GaSb

1.d. $M B E$ grown $p$ type AlSb

1.c' MBE grown $p$ type GaSb after 24 h.under ultra high vacuum.

1.d' MBE grown $p$ t.ype AISb after $24 \mathrm{n}$. under ultra high vacuum

Auger spectra during the growth of GaSb on ATSb

$e=$ thickness of $G a S b$ film $\left(A^{\circ}\right)$
Work function variations during the growth of $\mathrm{GaSb}$ on AlSb

$A$ is relative to etched $G$ aSb surfaces and 8 to clean and ordered GaSb surfaces 